\title{
Application of Analytic Hierarchy Process in Evaluating Higher Industry Vocational Colleges Financial Performance
}

\author{
Caiqin Chen ${ }^{1 \#}$, Dongping Wei ${ }^{2 \#}$, Zhoutao Chen ${ }^{3}$, Wentao Wang ${ }^{4 *}$ \\ ${ }^{I}$ College of Continuing Education and Training, Shenzhen Polytechnic, Shenzhen, China \\ ${ }^{2}$ Math and Physics Department, Shenzhen Polytechnic, Shenzhen, China \\ ${ }^{3}$ School of Journalism and Communication, The Chinese University of Hong Kong, Hong Kong, China \\ ${ }^{4}$ Development and Planning Office, Shenzhen Polytechnic, Shenzhen, China \\ *Corresponding Author. \\ \#Caiqin Chen and Dongping Wei contributed equally to this work.
}

\begin{abstract}
The financial performance should be evaluated from the perspective of stakeholders in higher vocational colleges firstly. And according to the development status of higher vocational colleges in recent years, a set of evaluation index of financial performance with characteristics of higher vocational colleges should be divided into five major dimensions: the performance of talents training, teaching performance, scientific research performance, performance of social services, logistics support performance. Hence, the financial performance evaluation model based on AHP and five major dimensions is established to solve the major theoretical and practical issues of financial performance evaluation and monitoring in higher vocational colleges. We also try to evaluate the financial performance of some benchmark industry and engineering vocational colleges applying the AHP model. Using statistical program $R$ to analysis the panel data, the results show that the reasonable standards and clear directions can improve the financial performance in higher vocational colleges.
\end{abstract}

Keywords: The financial performance evaluation, analytic hierarchy process, industry and engineering education.

\section{Introduction}

The financial performance evaluation of universities is started to study in aboard as early as 1980 s. A series of indicators is created to evaluate the financial performance in western countries. And the financial performance evaluation model plays a key role in the university evaluation system. Silva M F G D (2000) proposed that universities and colleges internal budget and resources allocation mechanism can be used as incentive instruments to improve quality and productivity [1]. Shinn J (2004) discussed performance budgeting and funding (PBF) programs had improved institutional performance of higher education over the five years (1997 through 2001) [2] .ZENG Fan-rong (2009) proposed an improved DEA method to study the evaluation of University's financial performance. They believed that the establishment of financial performance evaluation system should consider the following five aspects such as teaching performance, scientific research performance, self-financing ability, asset performance, and industry performance and so on [3]. Wu, H. Y tried to weight the performance evaluation indices for higher education based on the official performance evaluation structure developed by the Taiwan Assessment and Evaluation Association [4].Sexton T R (2012) proposed an efficiency-based mechanism for state funding of public colleges and universities using data envelopment analysis [5]. Han H, Sa Z (2013) introduces Potter' s competitive strategy theory into the university budget management, trying to build a budget performance evaluation system of local colleges based on focused strategy [6]. Zhen-Yu D U (2014) categorized the financial performance indexes of universities into three groups including internal indicators, operation and external indicators [7]. X Liu (2016) introduced Russia established performance evaluation system to promote higher education quality in development, based on principles, building moderate evaluation index system with clear evaluation content, methods. By applying the evaluation, Brazilian relevant parties can make correct decisions from the evaluation result; improve the use efficiency of higher education funds, which pushes higher education to develop continuously [8]. Moore A, Russ-Eft

ISSN: 0010-8189 
D (2016) examined the potential impact factors of the strategic enrollments. [9]. XU Yingke (2017) constructed the financial performance evaluation system of colleges and universities from the four dimensions of fiscal budgeting ability, income ability and running performance and solvency [10]. Using a difference-in-difference methodology, Hagood (2019) explored the performance of funds and its impact factors. Cao (2020) study the university financial performance and its impact factors when the functional mechanism and developing path are changing in some Chinese university[11].This article analyzes the financial performance evaluation from the perspective of stakeholders in Higher Vocational Colleges firstly. We also try to enrich the theoretical system of evaluation of financial performance in higher vocational colleges in our works.

\section{Notations and Methodology}

\subsection{Notations}

In order to clearly present the financial performance evaluation model and data analysis in the following four sections, we introduce the key definitions and notations of variables in the following.

$X$ :the pair-wise judgment matrix between different layers.

$x_{i j}$ : the relative importance or priority between two elements.

$R I$ : is random consistency index.

$C R$ : a consistent ratio of the comparison matrix.

$C I$ : the consistency index.

$\delta$ :The comprehensive performance index.

$\delta_{1}$ :personnel training performance index.

$\delta_{2}$ :teaching and research performance index.

$\delta_{3}$ :scientific research performance index.

$\delta_{4}$ :social service performance.

$\delta_{5}:$ logistical support performance index.

$w_{1}$ : the weight of personnel training performance index.

$w_{2}$ : the weight of teaching and research performance index.

$w_{3}$ : the weight of scientific research performance index.

$w_{4}$ : the weight of social service performance.

$w_{5}$ : the weight of logistical support performance index.

\subsection{The evaluation model under AHP Methodology}

Analytic hierarchy process (AHP) is proposed by T. L. Saaty, an American operations research scientist, University of Pittsburgh in the early 1970s. Analytic hierarchy process (AHP) can deal with various decision-making problem simple and effectively because it combines the qualitative analysis with the quantitative analysis. AHP is also simple and flexible for higher vocational college financial performance evaluation. According to the development status of Higher Vocational Colleges in recent years, a set of evaluation index of financial performance with characteristics of higher vocational colleges should be divided into five major dimensions: the performance of talents training, teaching performance, scientific research performance, performance of social services, logistics support performance. The five dimensions can be decomposed to 68 indictors from different angle. The following parts of this paper will further study the comprehensive financial performance evaluation model of Higher Vocational Colleges. The comprehensive financial performance evaluation model involves quantified dimension indicators. The weights of indicators can be gained by the evaluation model.

The hierarchical structure model is constructed according to the performance of five principles shown in Fig.1.The hierarchical structure includes five layers and some important factors. The first important layer can be defined as the key target layer: higher vocational college financial performance evaluation. The second layer is the criteria layer 
including personnel training performance, teaching and teaching scientific research performance, social services performance, logistics support performance. The third layer is a sub-criteria layer including students, faculties training performance, specialty construction and so on. The fourth layer is index layer contains a total of 68 sub-indicators.

$X$ is the pair-wise judgment matrix between the criterion layer with the target layer. The judgment matrixes represents the relative importance or priority comparing with all the elements (A-performance of training talents, B-teaching and research performance, C-scientific research performance, D-social service performance, E-logistics support performance) and the evaluation goal (Financial Performance Evaluation in Higher Vocational Technical College). $X$ can be calculated by the following equation,

$$
X_{5 \times 5}=\left[\begin{array}{cccc}
x_{11} & x_{12} & \mathrm{~L} & x_{14} \\
x_{21} & x_{22} & \mathrm{~L} & x_{24} \\
\mathrm{M} & \mathrm{M} & \mathrm{L} & \mathrm{M} \\
x_{51} & x_{52} & x_{53} & x_{54}
\end{array}\right]
$$

where $x_{i j}$ is the relative importance or priority between two elements. The relative importance between the two elements can be shown in Table. 1.

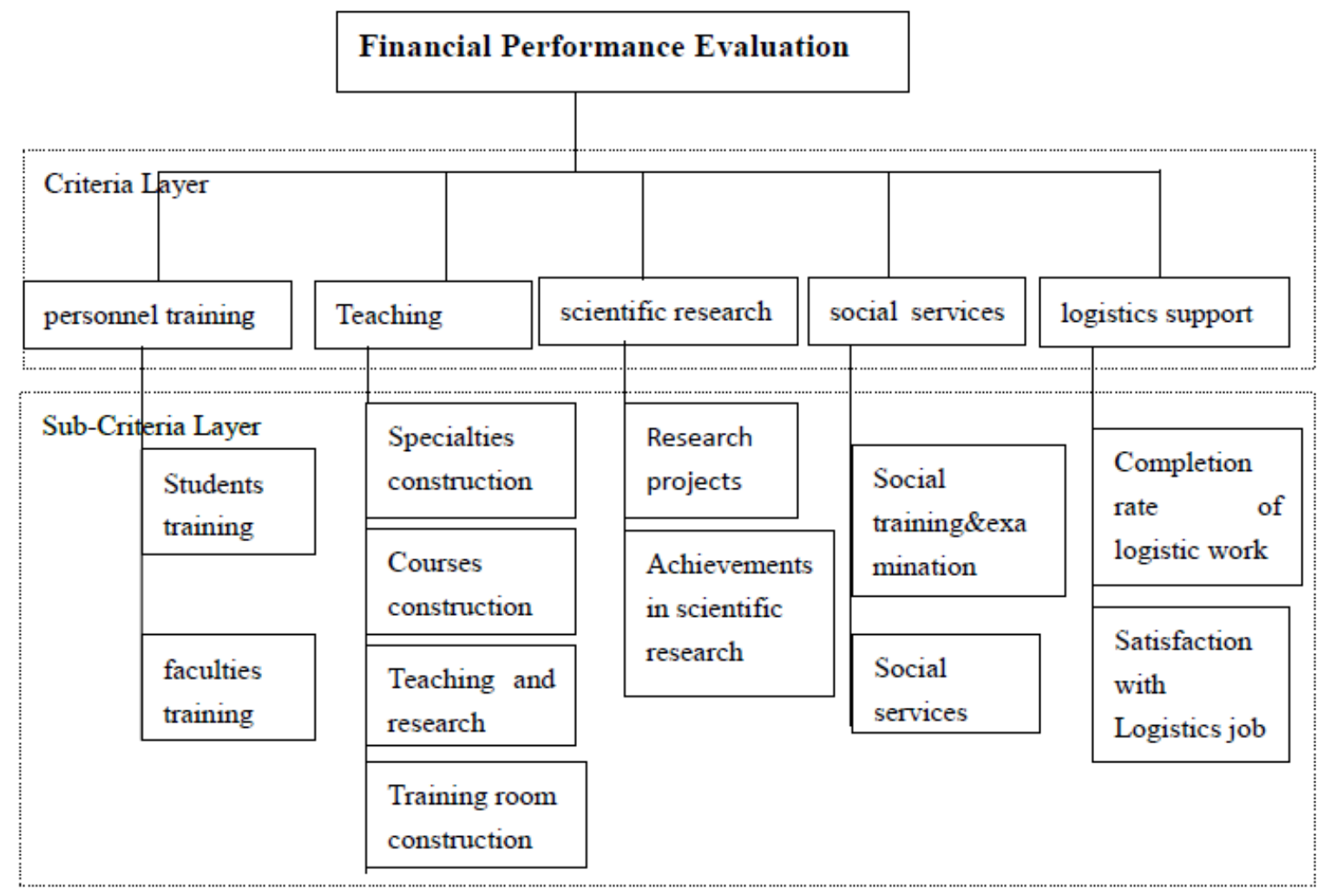

Fig.1 The hierarchical structure of financial performance evaluation in Higher Vocational Colleges

Table 1 The relative importance between the two element

\begin{tabular}{cccccccccc}
\hline & Equal & slightly important & More important & quite important & extremely important \\
\hline$x_{i j}$ & 1 & 2 & 3 & 4 & 5 & 6 & 7 & 8 & 9 \\
\hline
\end{tabular}

$x_{i j} \in[1,2]$ represents that element $\mathrm{i}$ and $\mathrm{j}$ are almost equal importance. $x_{i j} \in[3,4]$ represents that element $i$ and $j$ are slightly importance and so on. The pair-wise judgment matrix $X$ is generally a square matrix and has the 
following properties.

$$
(1) 0<x_{i j}<9 \text { (2) } x_{i i}=x_{j j}=1 \text { (3) } x_{i j}=1 / x_{j i}
$$

Property 1 shows the relative importance between the elements falls in the range of [0,9]. Property 2 shows that the diagonal elements in the pair-wise judgment matrix are equal to 1 . Property 3 shows the elements in upper triangular and lower triangular are symmetry reciprocally, which means that we only need to determine the upper triangular elements.

According to the AHP, we can adopt a consistent ratio to judge the consistent of the matrix. If $C R<0.1$, the consistency test is pass, otherwise the pair-wise comparison matrix needs to readjust. Generally the $C R$ value is smaller, then the consistency of judgment matrix is better. $C R$ is calculated as following

$$
C R=\frac{C I}{R I}
$$

$\mathrm{RI}$ is random consistency index can be obtained by the following Table. 2

Table 2 the random consistency index

\begin{tabular}{|l|l|l|l|l|l|l|l|l|l|}
\hline$n$ & 1 & 2 & 3 & 4 & 5 & 6 & 7 & 8 & 9 \\
\hline$R I$ & 0 & 0 & 0.58 & 0.9 & 1.12 & 1.24 & 1.32 & 1.41 & 1.45 \\
\hline
\end{tabular}

The consistency index $C I$ can be calculated as following

$$
C I=\frac{\lambda_{\max }-n}{n-1}
$$

and $\lambda_{\max }$ is the maximum Eigen-value in the determine matrix, $\mathrm{n}$ is the order of the matrix. The $\lambda_{\max }$ can be obtained by the following formula

$$
A W=\lambda W
$$

where $A_{n \times n}$ is a $n \times n$ square matrix, $W=\left(w_{1}, w_{2}, \cdots, w_{n}\right)$ is the eigenvector corresponding to the maximum Eigen-value matrix $\lambda$. The eigenvector $W$ can be obtained by the methods of characteristic polynomial method, iterative method, power method, etc. We use the geometric averaging method (root value method) to get the eigenvector $W$. The $\mathrm{i}$-th component of the eigenvector $W$ is

$$
\mathrm{w}_{\mathrm{i}}=\frac{\overline{\mathrm{w}_{\mathrm{i}}}}{\sum_{\mathrm{i}=1}^{\mathrm{n}} \overline{\mathrm{w}_{\mathrm{i}}}}
$$

where $w_{i}$ is the geometric mean of elements in $i$-th row of the square matrix $A_{n \times n}$.

$$
\overline{w_{i}}=\sqrt[n]{\prod_{j=1}^{n} a_{i j}}
$$

The maximum Eigen-value $\lambda_{\max }$ of the judgment matrix $\lambda$ can be obtained by following formula

$$
\lambda_{\max }=\sum_{i=1}^{n} \frac{(A W)_{i}}{n w_{i}}
$$

The eigenvector $W=\left(w_{1}, w_{2}, \cdots, w_{n}\right)$ is the weights vector of the indexes, where $\mathrm{w}_{\mathrm{i}}$ is the weight of the $\mathrm{i}$-th indicator element.

According to the hierarchical structure in the Fig.1, the linear weighted method can be used to calculate comprehensive financial performance evaluation index of Higher Vocational Colleges. The comprehensive index $\delta$ 
is weighted linear combination of personnel training performance index $\delta_{1}$, teaching and research performance index $\delta_{2}$, scientific research performance index $\delta_{3}$, social service performance $\delta_{4}$ and logistical support performance index $\delta_{5}$.

$$
\delta=w_{1} \delta_{1}+w_{2} \delta_{2}+w_{3} \delta_{3}+w_{4} \delta_{4+} w_{5} \delta_{5}
$$

where $w_{1}, w_{2}, w_{3}, w_{4}, w_{5}$ are the weight of personnel training performance index, teaching research index, scientific research performance index, social services performance index, logistical support performance index respectively.

\section{Data Analysis}

3.1 The discussion of data and dimensionless processing

Some indexes can promote the financial performance of higher vocational colleges, and some would depress the performance unfortunately. Hence, we can divide the indexes into two categories. Firstly, the positive indicators can promote the financial performance, such as the degree of satisfaction of graduates. Secondly, the negative indicators depress the performance, such as the complaint rate of rear services. Since we can't compare the financial performance indicators of Higher Vocational Colleges with different units, we must carry out dimensionless processing of all indicators. The commonly used dimensionless methods are standardization, mean value and range normalization. The standardization methods are shown as following

$$
\tilde{x}_{i}=\frac{x_{i}-\bar{x}_{i}}{\sigma_{x}}
$$

The mean value methods is shown as following

$$
\tilde{x}_{i}=\frac{x_{i}}{\bar{x}_{i}}
$$

Using the range normalization formula in this paper, the original value $\mathrm{x}_{\mathrm{i}}$ can be normalized to $\tilde{\mathrm{x}}_{\mathrm{i}}$ as following.

For positive indicators, $\tilde{x}_{i}$ can be calculated as

$$
\tilde{x}_{i}=\left\{\begin{aligned}
1 & x_{i} \geq x_{\max } \\
\frac{x_{i}-x_{\min }}{x_{\max }-x_{\min }} & x_{\min }<x_{i}<x_{\max } \\
0 & x_{i} \leq x_{\min }
\end{aligned}\right.
$$

For negative indicators, $\tilde{x}_{i}$ can be calculated as

$$
\tilde{x}_{i}=\left\{\begin{aligned}
1 & x_{i} \leq x_{\operatorname{mim}} \\
\frac{x_{\max }-x_{i}}{x_{\max }-x_{\min }} & x_{\min }<x_{i}<x_{\max } \\
0 & x_{i} \geq x_{\max }
\end{aligned}\right.
$$

where $x_{\max }$ is the maximum of samples, $x_{\min }$ represents the minimum of samples. After the normalization process, all samples have a unified dimension and $\tilde{x}_{i} \in[0,1]$.

\subsection{The Results of Empirical Analysis on financial performance with R program}

Shenzhen $\mathrm{XX}$ is a famous and benchmark higher vocational college in China. Its financial data have representativeness, we call it Benchmark College in the following section. We try to compare the financial performance of Benchmark College by the financial performance evaluation model vertically and horizontally. The data are accessed by Shenzhen XX Yearbook, Shenzhen XX students affairs division, financial department, 
scientific research department, personnel and other related departments, Shenzhen XX annual report, McKinsey survey data and so on. Using statistical program R to process the data, the financial performance of Benchmark College (2010-2015) based on financial performance evaluation model is shown in Tab.3.

We can see from Fig.2, financial performance index of benchmark college grows steadily in years 2010-2015 and declines slightly in 2011 and 2015.The financial performance index of benchmark college reaches the maximum value 75.08 in 2014. And the minimum of financial performance index of Benchmark College is 57.06. The variation tendency of the five sub-indexes can be observed from Fig.2 either. The personnel training performance index grows stably in years 2010-2015. The teaching and teaching scientific research index grows in 2010-2015 overall, but it declines in 2011 and 2012 slightly. The maximum value of the teaching and teaching scientific research is 57.11 and the minimum value is 18.62 . The index of scientific research performance rises steadily during 2010-2014, declines slightly in 2015. The social service performance index fluctuates in 2010-2015, but it is stable overall. The logistics support performance index in 2010-2015 fluctuates between 61.27-71.61. The trend of the logistics support performance index during 2013-2015 is downward slightly. The logistics support performance index rebounds after hitting rock bottom in 2013.

Table 3 financial performance score of Benchmark College

\begin{tabular}{|c|c|c|c|c|c|c|}
\hline score & 2010 & 2011 & 2012 & 2013 & 2014 & 2015 \\
\hline personnel training & 64.18 & 70.50 & 73.34 & 73.84 & 75.65 & 81.38 \\
\hline teaching & 37.38 & 18.62 & 31.56 & 44.79 & 57.11 & 45.85 \\
\hline scientific research & 49.85 & 56.93 & 69.06 & 81.61 & 86.70 & 74.05 \\
\hline social service & 79.14 & 73.96 & 72.27 & 72.49 & 77.25 & 89.34 \\
\hline logistics support & 68.51 & 71.61 & 66.77 & 61.27 & 64.15 & 69.79 \\
\hline composite index & 57.26 & 57.06 & 63.70 & 69.85 & 75.08 & 72.47 \\
\hline
\end{tabular}




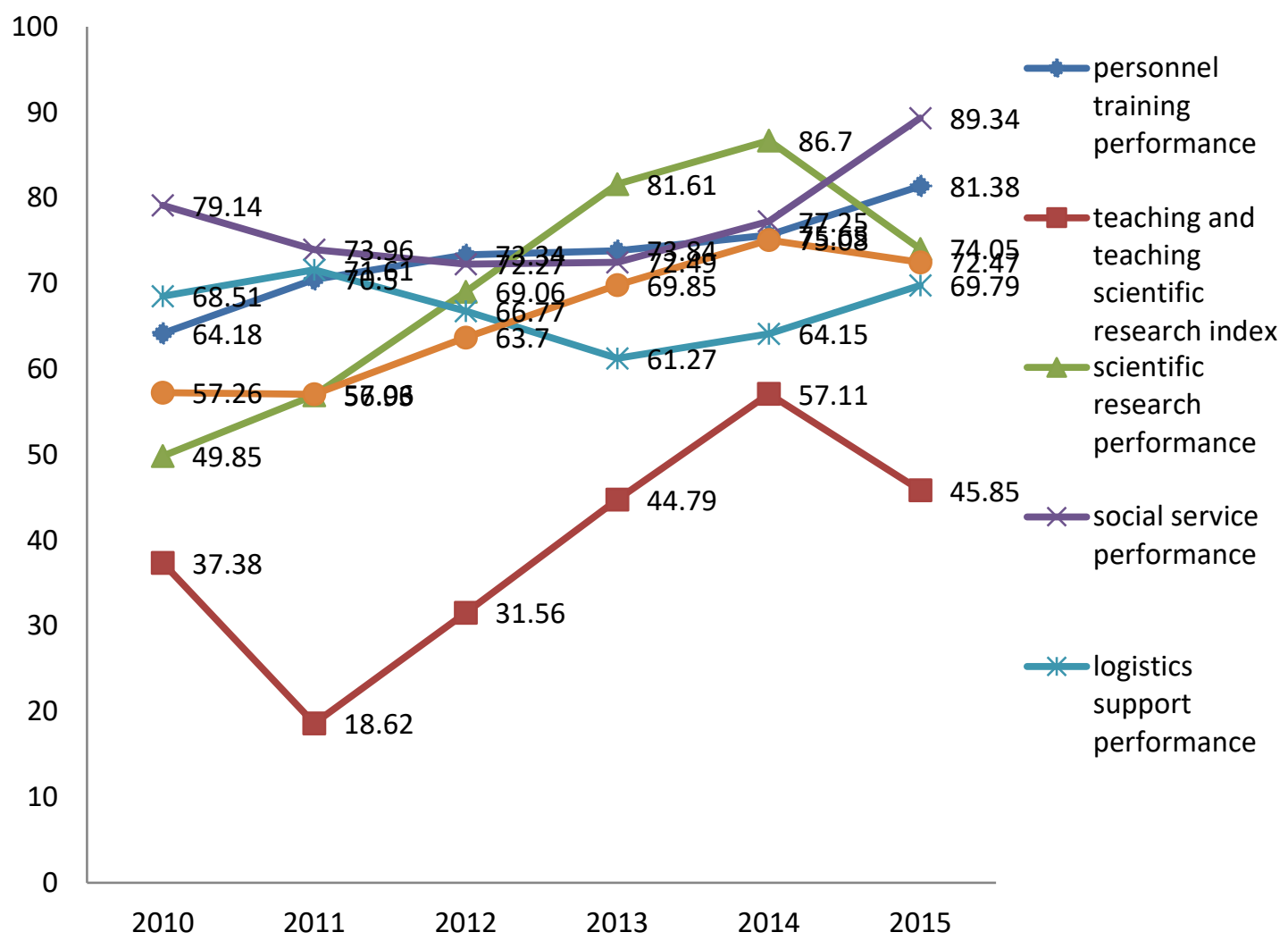

Fig 2: Financial performance evaluation of Benchmark College

\section{Conclusion}

The higher vocational college's financial performance evaluation model based on AHP is proposed in this paper. Shenzhen XX is benchmark of the vocational colleges. Hence, it is valuable to assess the financial performance of Benchmark College as the benchmark of higher vocational college's financial performance applying the model. According to the data, comprehensive performance index of Benchmark College grows steadily in 2010-2015. The data also indicate that benchmark college financial management has standard of reasonable and clear direction. And the financial management well reflects the personnel training mode of "three aspects of education" in Benchmark College. The effective and proper financial management of Benchmark College is the escort of training of high-quality professional personnel. We can still conclude that Benchmark College did not establish a complete financial performance evaluation index system. However, there is no clear and detailed series of financial performance objectives as the guidance in the implementation of financial. And the complete system of the financial performance of real-time monitoring and management system is not established either.

\section{Acknowledgements}

This work is supported by Project funded by 2020 innovation project of Education Department of Guangdong Province: 2019GKTSCX090.

\section{References}

[1] Silva, \& Marcos Fernandes Gonalves da, "Budgeting and resource allocation in universities: a public choice approach”, Revista De Administração De Empresas, vol. 40, no. 4, pp. 48-55, 2000.

[2] J. Shinn, S. Milton, "The effects of performance budgeting and funding programs on graduation rate in public four-year colleges and universities", Education Policy Analysis Archives, vol. 12, no. 12, pp. 786-797, 2004. 
[3] F.R Zeng, H.L. Zhang, "Study on evaluation of university's financial performance based on improved DEA method”, Scientific Decision Making, vol. 2009, no. 8, pp. 75-80, 2009.

[4] H.Y Wu, "Ranking universities based on performance evaluation by a hybrid Mcdm model", Measurement, vol. 45, no. 5, pp. 856-880, 2012.

[5] T.R. Sexton, C.L. Comunale, S.C. Gara, "Efficiency-Based Funding for Public Four-Year Colleges and Universities," Education Finance \& Policy, vol. 7, no. 3, pp. 1-29, 2012.

[6] H. Han, Z. Sa, "Performance evaluation of special funds based on budget management in colleges and universities", vol. 220, pp. 151-158, 2013.

[7] Zhen-Yu D U, Department F. "Comparative studies on the financial performance evaluation of Shaanxi local colleges and universities”, Journal of Shaanxi University of Technology, vol. 30, no. 1, pp. 75-78, 2014.

[8] X. Liu, "Performance evaluation of higher education expenditure of Russia", Journal of Central South University, vol. 20, no. 1, pp. 28-33, 2016.

[9] A. Moore, D. Russ-Eft, "Outcomes-Based Funding: Origins and Implications for the SEM Practitioner", Strategic Enrollment Management Quarterly, vol. 3, no. 4, pp. 261-281, 2016.

[10] Y.K. Xu, "On Financial Performance Evaluation of Colleges and Universities Based on Gray relational Analysis", Journal of Xinjiang University of Finance and Economics, vol. 4, pp. 46-55, 2017.

[11] Q. Cao, M. Tan, Q. Yu, P. Wang, "Research on the quantity, quality and economic performance of scientific research achievements in Chinese universities," Technology Analysis and Strategic Management, vol. 32, no. 12, pp. 1-14, 2020.

[12] L.P. Hagood, "The financial benefits and burdens of performance funding in higher education", Educational Evaluation and Policy Analysis, vol. 41, no. 2, pp. 189-213, 2019. 